ORIGINAL ARTICLE

\title{
CYP1B 1 mutations in French patients with early-onset primary open-angle glaucoma
}

\author{
R Melki, E Colomb, N Lefort, A P Brézin, H-J Garchon
}

J Med Genet 2004;41:647-651. doi: 10.1136/jmg.2004.020024

See end of article for authors' affiliations

.....................

Correspondence to: H-J Garchon, INSERM U580, Hôpital Necker, 161 rue de Sèvres, 75743 Paris, Cedex 15, France; garchon@necker.fr

Revised version received 1 April 2004

Accepted for publication 5 April 2004
Introduction: Primary open-angle glaucoma (POAG) is a leading cause of visual impairment worldwide and a complex genetic disorder that affects mostly adults. Mutations in the MYOCILIN (MYOC) and OPTINEURIN genes account for rare forms with a Mendelian inheritance and for $<5 \%$ of all POAG cases. The CYP1B 1 gene, a member of the cytochrome P450 gene family, is a major cause of primary congenital glaucoma (PCG), a rare and severely blinding disease with recessive inheritance. However, CYPIB1 mutations have also been associated with cases of juvenile-onset glaucoma in some PCG families or shown to modify the age of onset of glaucoma linked to a MYOC mutation in a large family.

Objective: To investigate the role of CYP1B1 mutations in POAG predisposition, irrespective of the presence of a MYOC mutation.

Methods and subjects: CYPIBI coding region variation was characterised by denaturing high performance liquid chromatography (DHPLC) and sequencing in 236 unrelated French Caucasian POAG patients and 47 population-matched controls.

Results: Eleven (4.6\%) patients carried one or two mutated CYPIB1 gene(s) and no MYOC mutation. They showed juvenile or middle-age onset of disease (median age at diagnosis, 40 years, range 13-52), significantly earlier than in non-carrier patients. Apart from one, all mutations detected in POAG patients were previously associated with PCG.

Conclusion: CYPIB 1 mutations might pose a significant risk for early-onset POAG and might also modify glaucoma phenotype in patients who do not carry a MYOC mutation.
$\mathrm{P}$ rimary open-angle glaucoma (POAG) is an optic neuropathy characterised by an excavation of the optic disk and a progressive alteration of the visual field. It is a leading cause of visual impairment, affecting 66 million persons worldwide. ${ }^{12}$ Genetic factors play a well-established but complex role in POAG predisposition. ${ }^{3}$ Six loci with a Mendelian inheritance have been mapped using large multicase families. ${ }^{5}$ Two of these, including GLCIA/MYOCILIN (MYOC) and GLCIE/OPTINEURIN (OPTN), have been identified at the molecular level. ${ }^{6}{ }^{7}$ In most cases, however, and in spite of clear familial clustering, POAG does not follow a Mendelian pattern of inheritance. Mutations of MYOC have been detected in a minor $(2-4 \%)$ proportion of the most frequent cases. ${ }^{8}$ Altogether, the genetic basis of POAG remains unknown in the majority of patients. Identifying genetic factors associated with this prevalent disease is nonetheless of substantial research and clinical importance.

Primary congenital glaucoma (PCG) is a rare ocular disorder characterised by marked elevation of intraocular pressure (IOP) at birth or in early childhood, leading to ocular enlargement (buphthalmos) and corneal oedema. ${ }^{9}$ If it is not urgently treated, optic nerves are irreversibly damaged and vision may be lost. This severe defect is mostly inherited in an autosomal recessive manner. ${ }^{10}$ A major gene, CYPIBI, belonging to the superfamily of cytochromes P450 and mapping on chr.2p2l, has been identified. ${ }^{11}{ }^{12}$ A broad diversity of mutations in this gene has been characterised in different populations. ${ }^{13-19}$

PCG is currently considered as a consequence of a developmental defect of the iridocorneal angle and a clinical and pathogenetic entity distinct from POAG. ${ }^{9}$ In certain pedigrees, however, both PCG and POAG segregate, suggesting that shared or overlapping mechanisms might predispose to both forms of glaucoma. The identification of CYPIBI provides an opportunity to test this hypothesis. Indeed, three studies have reported delayed expression of a CYPIBI mutation and co-existence of PCG and POAG in the same pedigree. ${ }^{19} 2021$ Moreover, in a large family where MYOClinked POAG segregated, a heterozygous mutation of CYPIBI was associated with earlier onset of the disease in patients carrying the MYOC mutation, indicating that a CYPIBI mutation might behave as a modifier of the MYOC gene. ${ }^{21}$

Considered collectively, these observations suggested that mutations of CYPIBI might be a cause of POAG or at least a risk factor for this disease. In the present study, we report two additional pedigrees with both POAG and PCG patients carrying CYPIB1 mutations. This led us to investigate CYPIBI mutations in a group of 236 French patients with POAG.

\section{METHODS \\ Patients}

POAG patients were recruited at the Glaucoma Institute of Saint-Joseph Hospital and at the Quinze-Vingts Hospital in Paris, and at the Lille University Hospital as described. ${ }^{22}$ Probands of PCG families were reported previously. ${ }^{18} \mathrm{~A}$ protocol approved by the Ethics Committee of Necker Medical School and in keeping with European legislation was followed. Written informed consent was obtained from all patients or, for children, from their parents. Ophthalmologic examination included slit-lamp biomicroscopy, optic nerve examination, measurement of IOP by applanation tonometry, and visual field assessment by automated perimetry. POAG was defined by the conjunction of a normally open iridocorneal angle, characteristic cupping of the optic disk, and alteration of the visual field. Patients

Abbreviations: DHPLC, denaturing high performance liquid chromatography; DMSO, dimethylsulfoxide; IOP, intraocular pressure; PCG, primary congenital glaucoma; POAG, primary open-angle glaucoma; TEAA, triethylammonium acetate 
with cataract or media opacities and those with a cause of secondary glaucoma, notably including exfoliation, pigment dispersion, history of trauma, surgery, and glucocorticoid exposure, were excluded. Elevation of IOP was not an inclusion criterion. Final POAG diagnosis was made at the time of inclusion after review of inclusion and exclusion criteria, and before genotyping was conducted. Genotyping was performed blind to clinical data. All patients had been screened for MYOCILIN mutations by denaturing high performance liquid chromatography (DHPLC). Seventeen of these patients carried a $M Y O C$ mutation. ${ }^{22}$

\section{CYP1B 1 mutation search}

Two methods were employed when searching for mutations in CYPIBI (GenBank accession number: U56438). First, most of the coding region, including exon II and the $3^{\prime}$ half of the coding region of exon III, could be screened by denaturing high performance liquid chromatography (DHPLC). Pilot experiments indicated that all the mutations that had been characterised in PCG patients from France, ${ }^{18}$ were reliably detected by this method. Overlapping fragments ranging from 302 to 456 base pairs were amplified by PCR using the primers and conditions shown in table 1. The PCR was performed in a $25 \mu \mathrm{l}$ mixture containing $100 \mathrm{ng}$ of genomic DNA, $0.4 \mu \mathrm{mol} / \mathrm{l}$ of forward and reverse primers, $1.5 \mathrm{mmol} / \mathrm{l}$ $\mathrm{MgCl}_{2}, 5 \%$ dimethylsulfoxide (DMSO), $200 \mu \mathrm{mol} / \mathrm{l}$ of each dNTP, and $0.5 \mathrm{U}$ of Taq DNA polymerase (Invitrogen, Life Technologies, Carlsbad, CA, USA). Cycling conditions for each cycle were: $1 \mathrm{~min}$ at $94^{\circ} \mathrm{C}, 1 \mathrm{~min}$ at an annealing temperature specific to each amplicon (shown in table 1), and $1 \mathrm{~min}$ at $72^{\circ} \mathrm{C}$, for 35 cycles. DHPLC analysis was conducted with the Wave Nucleic Acid Fragment Analysis System (Transgenomic, Omaha, NE). The oven temperature and gradient conditions for heteroduplex detection were predicted with WaveMaker software (version 4.1.40) and specified experimentally as described previously. ${ }^{22}$ Actual parameters for DHPLC analysis of CYPIBI amplicons were established in this work and are listed in table 1. PCR products from DNA to be tested were mixed with an equimolar amount of PCR product from a DNA sample known to be unmutated. This DNA carried the common SNPs forming the most frequent haplotype in the French population (C3947G, G4160T, C8131G, C8184T, A8195G). The mixture was heated at $95^{\circ} \mathrm{C}$ for $5 \mathrm{~min}$ and allowed to cool at room temperature for $30 \mathrm{~min}$ to form heteroduplexes. A $5 \mu \mathrm{l}$ sample was loaded on a DNA Sep Column (Model L$7300+$, Transgenomic) and was eluted with a linear gradient of $5 \%$ triethylammonium acetate (TEAA) (buffer A) and 25\% acetonitrile $+5 \%$ TEAA (buffer B) at a flow rate of $0.9 \mathrm{ml} / \mathrm{min}$. Elution profiles were compared to those of normal DNA. Samples with altered profiles were considered as potentially having a sequence variation and were sequenced bidirectionally as previously. ${ }^{13}{ }^{14}$ Representative profiles are shown in the online supplemental fig 1 (available at http://jmg.bmjjournals. com/supplemental/).

In contrast, the $5^{\prime}$ end of exon III was not amenable to DHPLC analysis. This DNA segment contains three common SNPs. Their various combinations generate a diversity of elution profiles that complicates the detection of mutations. The corresponding amplicon was therefore sequenced directly.

\section{RESULTS \\ POAG and PCG in two French families with CYP1B 1 mutations}

In the pedigree shown in fig $1 \mathrm{~A}$, two sisters, including the proband, were affected with PCG whereas the other two sisters developed POAG at ages 35 and 40. The four sisters carried the same two mutations of CYPIB1, G232R and
E387K. Similarly, in the pedigree shown in fig $1 \mathrm{~B}$, the proband developed juvenile-onset glaucoma at the age of 13 . Subsequently, it was found that his younger brother was affected with PCG, which led to investigation of CYPIBI in this family. Both brothers carried the same two mutations, 3979delA and N423Y.

\section{CYP1B 1 mutation screen in 236 unrelated POAG patients}

Sequence variation in the CYPIBI gene coding region was then investigated in a group of 236 unrelated Caucasian patients with POAG from France. Altogether, 11 patients carried a mutation of CYPIBI (table 2). None of them carried a MYOCILIN mutation. One of the CYPIBI mutations, Y81N, is new. It was present in the heterozygous state in two unrelated patients. It is likely to be pathogenic because the amino acid change is non-conservative while the tyrosine residue at this position is highly conserved across species in the CYPl gene family and even among other members of the cytochrome P450 superfamily (see online supplemental fig 2 , available at http://jmg.bmjjournals.com/supplemental/). In addition, one of the two patients (patient $\mathrm{C}$ ) was the father of two children who developed early-onset glaucoma, with ages at onset of 39 and 44 and who both carried the mutation (fig 2). Finally, the mutation was not detected in 394 control chromosomes (see below).

All other mutations encountered in this group of POAG patients were previously observed in PCG patients, in France or elsewhere. The patient A with juvenile-onset glaucoma and with a compound heterozygous mutation (table 2) was described above (fig 1B). He was included as he was the proband of his family. For all other patients, no family history of PCG was recorded. In particular, they were unrelated to French PCG patients previously studied. ${ }^{18}$ One mutation, 269delSNF, was homozygous. The carrier was of French descent, whereas the mutation was initially described in PCG patients from Saudi Arabia and, in France, in families originating from North Africa. ${ }^{18} 23$ All other mutations were heterozygous. The heterozygous E229K mutation was previously associated with PCG in two French cases. ${ }^{18}$ Two other mutations, including 7901_7913delGAGTGCAGGCAGA (two cases) and R390H (one case), were previously associated with PCG in conjunction with a CYPIBI mutation on the other chromosome..$^{13} 18$ The last mutation, A443G, has been observed in Caucasian PCG patients from different countries. ${ }^{15}{ }^{17}$ In the three French POAG patients, it was associated with one or two rare synonymous variants, including G4534C (V243V) and T7915C (L360L). The latter variant has not been described before. The A443G mutation has not been observed in Caucasian controls. ${ }^{13}{ }^{14}$ Interestingly, a recent report indicated that it could be a common variant in an African population, with a frequency of $7 \%{ }^{24}$ The study, however, included no assessment of vision while POAG is more frequent $(5-10 \%)$ and occurs earlier in black than in white subjects. ${ }^{2}{ }^{3}$ With this caveat, the pathogenic property of A443G might be population-specific, perhaps because it depends on other factors, themselves population-specific. Alternatively, the mutation might be in linkage disequilibrium with an actually pathogenic variant in Caucasians.

Besides the above described mutations, the six common SNPs previously reported including T3793C, R48G, Al19S, V432L, D449S, and N453S were also observed in POAG patients. ${ }^{14171823}$ None of these SNPs nor a particular haplotype formed by them was preferentially associated with the mutations (not shown). The rare synonymous variant G4534C (V243V) was detected by itself in one case. No other $C Y P 1 B 1$ variant was detected in the POAG group. Previous reports of Caucasian controls totalling 150 persons from three populations, in the United Kingdom, Turkey, and Saudi 
Table 1 Primer sequences of CYPIBI amplicons, PCR conditions, and DHPLC analysis parameters

\begin{tabular}{|c|c|c|c|c|c|c|}
\hline Amplicon & Primer sequences $\left(5^{\prime}\right.$ to $\left.3^{\prime}\right)$ & $\begin{array}{l}\text { PCR product } \\
\text { size (bp) }\end{array}$ & $\mathrm{MgCl}_{2}(\mathrm{mM})$ & $\begin{array}{l}\text { Annealing } \\
\text { temperature ('C) }\end{array}$ & $\begin{array}{l}\text { Acetonitrile gradient } \\
(\% \mathrm{~B}) \text {, start-end }\end{array}$ & Oven temperature ( $\left({ }^{\circ} \mathrm{C}\right)$ \\
\hline Exon 2_A & $\begin{array}{l}\text { F: CGCTCCTGTCTCTGCACCCC } \\
\text { R: GGCGCGGCGCTACGGCGACG }\end{array}$ & 302 & 0.5 & 60 & $\begin{array}{l}57-63 \\
53-59\end{array}$ & $\begin{array}{l}65 \\
69\end{array}$ \\
\hline Exon 2_B & $\begin{array}{l}\text { F: TGGCCACTGATCGGAAACGC } \\
\text { R: CCAACGTCATGAGTGCCGTG }\end{array}$ & 456 & 1 & 57 & $\begin{array}{l}61-67 \\
59-65\end{array}$ & $\begin{array}{l}67 \\
70\end{array}$ \\
\hline Exon 2_C & $\begin{array}{l}\text { F: GCCACGTGCTGAGCGAGGCG } \\
\text { R: CATCCTGGACAAGTCTTGA }\end{array}$ & 329 & 1 & 57 & $\begin{array}{l}58-64 \\
57-63 \\
52-58\end{array}$ & $\begin{array}{l}65 \\
66.5 \\
71\end{array}$ \\
\hline Exon 2_D & $\begin{array}{l}\text { F: GGTGCGCACCGITTCCGCG } \\
\text { R: GGGTTGGGGTTCGCTCCA }\end{array}$ & 395 & 1 & 55 & $\begin{array}{l}59-65 \\
57-63\end{array}$ & $\begin{array}{l}62 \\
64.5\end{array}$ \\
\hline Exon 3_B & $\begin{array}{l}\text { F: GAGAACTTTGATCCAGCTCG } \\
\text { R: GCAAGAGGCAAGCTGAAATT }\end{array}$ & 343 & 1 & 55 & $\begin{array}{l}58-64 \\
55-61\end{array}$ & $\begin{array}{l}58 \\
60.5\end{array}$ \\
\hline
\end{tabular}

Arabia, indicated an absence of CYPIBI variants apart from the six common SNPs. ${ }^{13}{ }^{14}$ We also searched for CYPIBI variants in 47 French Caucasian controls who were spouses belonging to large families of POAG patients carrying a MYOCILIN mutation. Based on gonioscopy, on assessment of the optic disks, and on an IOP measurement in the normal range, their ophthalmic examination was estimated to be normal. The mutation screening protocol was exactly the

A

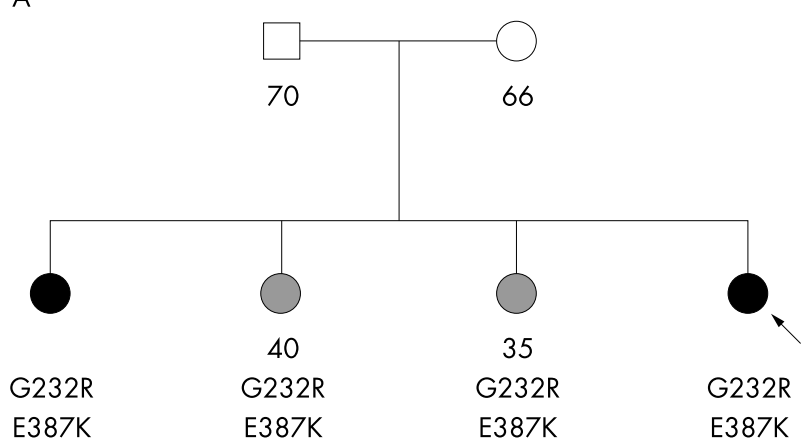

B

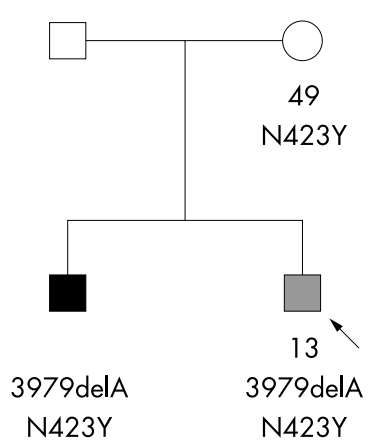

Figure 1 Variable expressivity of CYPIB1 mutations in two sibships. The arrows show the probands. Available genotypes and ages at diagnosis or at examination are indicated below the symbols. (A) Four sisters, all carrying two missense mutations, G232R and E387K. Two were affected with PCG (dark symbol) while the other two developed POAG (hatched symbol). The parents, who are obligate carriers, showed no glaucoma symptom at the indicated ages. Because they could not be genotyped, the phase of both mutations is unknown. (B) Two brothers, both carrying a deletion mutation (3979delA) and a missense mutation (N423Y). The proband developed juvenile glaucoma at the age of 13, while his younger brother showed PCG. Their mother carried the missense mutation and showed no glaucoma symptom at the age of 49 . Their father could not be examined. same as that used for the group of patients. One mutation, R368H, which was previously associated with PCG, ${ }^{17}$ was detected on one chromosome (table 3 ). Three synonymous variants, including C3851T (L16L) (one case), C4369A (Gl88G) (two cases), and V243V (two cases) were also found.

Altogether, the finding of 11 mutation carriers among 236 patients $(4.6 \%)$ compared to one carrier in 197 controls (47 French+150 previously reported controls) is significant (twosided exact $\mathrm{p}=0.008$ ). Also, if one considers a prevalence of $2.85 \times 10^{-5}$ for PCG cases in Western countries, ${ }^{25}$ the expected frequency for heterozygotes is approximately $1 \%$, assuming a recessive mode of inheritance and under the condition of Hardy-Weinberg equilibrium. The finding of 11 mutation carriers among 236 subjects is significant (two-sided $\mathrm{p}$ value using a binomial law $=0.0001$, with the null hypothesis of a probability value of 0.01 ). The calculation, however, is conservative because one of the POAG patients had a homozygous mutation while the heterozygous E229K mutation is associated with PCG in France and also because all PCG cases are assumed to be caused by CYPIBI mutations.

\section{Clinical features of CYP1B 1 carriers with POAG}

All patients listed in table 2 had definite bilateral POAG with cupping of their optic discs and significant alteration of their visual field. Evolution of glaucoma was severe enough to require either surgical therapy on both eyes (four patients), argon laser trabeculoplasty on both eyes (one patient), or surgical therapy on one eye and medical bi- or tri-therapy on the other eye (four patients). Of note, their iridocorneal angle was recorded as being normal. The most remarkable feature was their young age at the time of diagnosis, with a median of 40 years (range: 13-52). Epidemiologic studies indicate that the prevalence of POAG is 5-10 times lower before the

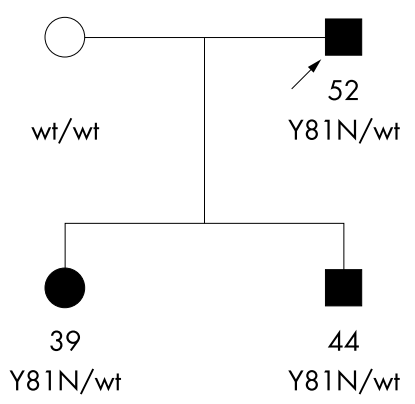

Figure 2 Pedigree showing cosegregation of the heterozygous Y81N CYPIB 1 mutation with POAG (solid symbols). The arrow shows the proband. Available genotypes and ages at diagnosis are indicated below the symbols. 


\begin{tabular}{|c|c|c|c|c|c|c|c|}
\hline Patient & Mutation & Exons & Effect & Status & Age (years) & $\begin{array}{l}\text { IOP }(\mathrm{mm} \mathrm{Hg}) \\
\text { OS/OD }\end{array}$ & $\begin{array}{l}\text { Rare CYPIB1 } \\
\text { polymorphisms }\end{array}$ \\
\hline A & 3979 delA+A8104T & $2+3$ & $\begin{array}{l}\text { Frameshift and } \\
\text { stop at } 59+\mathrm{N} 423 \mathrm{Y}\end{array}$ & $\begin{array}{l}\text { Compound } \\
\text { heterozygote }\end{array}$ & 13 & $42 / 42$ & \\
\hline B & T4046A* & 2 & Y81N & Heterozygous & 52 & NA & \\
\hline c & T4046A & 2 & Y81N & Heterozygous & 37 & $28 / 28$ & \\
\hline D & G4490A & 2 & E229K & Heterozygous & 35 & $25 / 21$ & \\
\hline $\mathrm{E}$ & $\begin{array}{l}7901 \text { 7913 } \\
\text { delGAGTGCAGGCAGA }\end{array}$ & 3 & $\begin{array}{l}\text { Frameshift+stop } \\
\text { at } 422\end{array}$ & Heterozygous & 50 & $20 / 20$ & \\
\hline $\mathrm{F}$ & $\begin{array}{l}7901 \text { 7913 } \\
\text { delGAGTGCAGGCAGA }\end{array}$ & 3 & $\begin{array}{l}\text { Frameshift+stop } \\
\text { at } 422\end{array}$ & Heterozygous & 40 & $26 / 36$ & \\
\hline G & 4611 4619 delGCAACTTCA & 2 & 269delSNF & Homozygous & 51 & $40 / 32$ & \\
\hline H & G8006A & 3 & $\mathrm{R} 390 \mathrm{H}$ & Heterozygous & 26 & $25 / 25$ & \\
\hline 1 & C8165G & 3 & A443G & Heterozygous & 48 & $30 / 30$ & V243V, L360L $\dagger$ \\
\hline $\mathrm{J}$ & C8165G & 3 & A443G & Heterozygous & 36 & $20 / 20$ & V243V \\
\hline $\mathrm{K}$ & C8165G & 3 & A443G & Heterozygous & 31 & $25 / 25$ & L360L \\
\hline L & & 2 & & Heterozygous & 50 & $30 / 30$ & V243V \\
\hline
\end{tabular}

age of 60 compared to that after this age. ${ }^{326}$ Therefore, CYPIBI mutations were typically associated with juvenile and middle-age onset POAG. Moreover, although the age at diagnosis in the whole group of patients also was young (median: 48; range: 6-81; interquartile range: $37-58$ ), the age at diagnosis of CYPIBI carriers was nonetheless younger than that of non-carriers ( $\mathrm{p}=0.023$, Mann-Whitney test).

\section{DISCUSSION}

Our data demonstrate an increased prevalence of CYPIBI mutations among French POAG patients. They extend the previous findings of Vincent et al, ${ }^{21}$ indicating that mutations in the $C Y P I B 1$ gene, nearly all of which were previously associated with PCG, are a significant risk factor for earlyonset POAG also in patients who do not carry a MYOC mutation. Because parents of PCG patients, who carry heterozygous mutations of CYPIB1, are apparently not at increased risk of developing glaucoma (see Bejjani et $\mathrm{al}^{23}$ and this work), gene dosage is unlikely to be a general mechanism for delayed expression of heterozygous mutations. Additional factors are probably necessary for development of the glaucomatous process. Apart from a mutation of the $M Y O C$ gene, a modifier locus influencing penetrance of CYPIB1 mutations has been described. ${ }^{23}$ This locus or a similar one could explain the delayed onset of disease in patients with a homozygous mutation or in compound heterozygotes. Moreover, in an experimental mouse model with a knock-out cyplbl gene, a recent report indicated that an alteration of the dopamine pathway could markedly exacerbate mild ocular symptoms associated with a defective cyplbl gene. ${ }^{27}$ Alternatively, one of the hallmarks of the CYPIBI gene is its inducibility by xenobiotics and by mutagenic chemicals. ${ }^{28}$ Therefore, onset of glaucoma in CYPIBI mutation carriers might be caused by exposure to an environmental factor of this kind.

\begin{tabular}{lllll}
$\begin{array}{l}\text { Table } 3 \\
\text { controls }\end{array}$ & CYP1B1 & mutation and variants in 47 French \\
\hline DNA variant & Exon & Occurrences ( $n$ ) & Codon & Effect \\
\hline G7940A & 2 & 1 & 368 (Arg) & Change $>$ His \\
C $3851 T$ & 2 & 1 & 16 (Leu)* & Synonymous \\
C4369A & 2 & 2 & $188($ Gly) & Synonymous \\
G4534C & 2 & 2 & 243 (Val) & Synonymous \\
\hline${ }^{*}$ New variant. & & & \\
\hline
\end{tabular}

Intriguingly, the IOPs of CYPIBI mutation carriers at the time of diagnosis were variable, ranging from borderline $(20 \mathrm{~mm} \mathrm{Hg})$ to markedly elevated $(40 \mathrm{~mm} \mathrm{Hg})$. Given that marked elevation of IOP is a prominent feature of PCG, the observation of normal to moderately elevated IOP measurements was unexpected. However, the recent discovery of expression of CYPIBI in the posterior segment of the eye, notably in the neuroretina, ${ }^{29}$ strongly suggests that mechanisms that do not depend directly on IOP elevation may also explain a role for CYPIBI in glaucoma pathogenesis. For example, accumulation of a toxic substrate as a result of a defective CYPIBI gene would result in greater sensitivity of neural ganglial cells to other stress factors and notably would lower the threshold necessary for IOP to cause damage to the optic nerve.

Although mutations of the CYPIBI gene have been identified in PCG patients from different populations, the frequency of the mutations, their nature, and their diversity vary greatly with the population studied. Similarly, the role of MYOC mutations in POAG appears to very much depend on the ethnic origin of the patients. ${ }^{22}{ }^{30}$ It will be therefore important to reproduce our findings in different groups of patients, considering both clinical and population factors in their selection, perhaps by means of a multinational collaborative study.

Identifying CYPIBI mutations in persons at risk of developing glaucoma, particularly among relatives of POAG patients, is of considerable clinical interest. It should help to monitor vision and to detect early symptoms of POAG in these persons. Because simple treatments are already available and operate optimally when they are given at an early stage of the disease, mutation screening for CYPIBI could contribute to preventing the visual impairment caused by glaucoma. Finally, common polymorphisms of the CYPIBI gene have been reproducibly associated with varying risks of developing several cancers, ${ }^{31}{ }^{32}$ whereas in mice inactivation of cyplbl was associated with an increased resistance to chemically-induced lymphomas. ${ }^{33}$ The observation of subjects with null alleles of CYPIBI therefore should provide invaluable insight into the role of CYP1BI in carcinogenesis ${ }^{34}$ as well as in other physiological processes involving this gene in the human species.

\section{ACKNOWLEDGEMENTS}

We are grateful to Dr Françoise Valtot, Dr Jean Claude Dascotte, and Professor Alain Béchetoille for providing access to the clinical records of their patients. 


\section{Authors' affiliations}

R Melki, E Colomb, N Lefort, H-J Garchon, INSERM U580, Hôpital

Necker, Paris, France

R Melki, Laboratoire de Biologie Cellulaire et Moléculaire, Université Ibnou Zohr, Agadir, Morocco

A P Brézin, Ophthalmology Unit, C.H.U. Cochin, Paris, France

This work was supported by INSERM (Institut National de la Santé et de la Recherche Médicale), by the Assistance Publique des Hôpitaux de Paris (grant DRRC-AOM96110), by the Fondation pour la Recherche Médicale, and by Insite Vision Inc. (Alameda, CA). RM was awarded a fellowship of the Comite Mixte Inter-Universitaire Franco Marocain (Al 237/SVS/2000).

Conflict of interest: none declared.

\section{REFERENCES}

1 Quigley HA. Open-angle glaucoma. N Engl J Med 1993;328:1097-106.

2 Quigley HA. Number of people with glaucoma worldwide. Br J Ophthalmol 1996;80:389-93.

3 Leske MC. The epidemiology of open-angle glaucoma: a review. Am J Epidemiol 1983;118:166-91.

4 Hulsman CA, Houwing-Duistermaat JJ, Van Duijn CM, Wolfs R, Borger PH, Hofman A, De Jong PT. Family score as an indicator of genetic risk of primary open-angle glaucoma. Arch Ophthalmol 2002;120:1726-31.

5 WuDunn D. Genetic basis of glaucoma. Curr Opin Ophthalmol 2002;13:55-60

6 Stone EM, Fingert JH, Alward WL, Nguyen TD, Polansky JR, Sunden SL, Nishimura D, Clark AF, Nystuen A, Nichols BE, Mackey DA, Ritch R, Kalenak JW, Craven ER, Sheffield VC. Identification of a gene that causes primary open angle glaucoma. Science 1997;275:668-70.

7 Rezaie T, Child A, Hitchings R, Brice G, Miller L, Coca-Prados M, Heon E, Krupin T, Ritch R, Kreutzer D, Crick RP, Sarfarazi M. Adult-onset primary open-angle glaucoma caused by mutations in optineurin. Science 2002;295:1077-9.

8 Fingert JH, Heon E, Liebmann JM, Yamamoto T, Craig JE, Rait J, Kawase K, Hoh ST, Buys YM, Dickinson J, Hockey RR, Williams-Lyn D, Trope G, Kitazawa Y, Ritch R, Mackey DA, Alward WL, Sheffield VC, Stone EM. Analysis of myocilin mutations in 1703 glaucoma patients from five differen populations. Hum Mol Genet 1999;8:899-905.

9 deLuise VP, Anderson DR. Primary infantile glaucoma (congenital glaucoma). Surv Ophthalmol 1983;28:1-19.

10 François J. Congenital glaucoma and its inheritance. Ophthalmologica 1980;181:61-73

11 Sarfarazi M, Akarsu AN, Hossain A, Turadi ME, Aktan SG, BarsoumHomsy M, Chevrette L, Sayli BS. Assignment of a locus (GLC3A) for primary congenital glaucoma (buphthalmos) to $2 \mathrm{p} 21$ and evidence for genetic heterogeneity. Genomics 1995;30:171-7

12 Stoilov I, Akarsu AN, Sarfarazi M. Identification of three different truncating mutations in cytochrome P4501B1 (CYP1B1) as the principal cause of primary congenital glaucoma (buphthalmos) in families linked to the GLC3A locus on chromosome 2p21. Hum Mol Genet 1997;6:641-7.

13 Bejiani BA, Lewis RA, Tomey KF, Anderson KL, Dueker DK, Jabak M, Astle WF, Otterud B, Leppert M, Lupski JR. Mutations in CYP1B1, the gene for cytochrome $\mathrm{P} 4501 \mathrm{~B} 1$, are the predominant cause of primary congenital glaucoma in Saudi Arabia. Am J Hum Genet 1998:62:325-33

14 Stoilov I, Akarsu AN, Alozie I, Child A, Barsoum-Homsy M, Turacli ME, Or M, Lewis RA, Ozdemir N, Brice G, Aktan SG, Chevrette L, Coca-Prados M, Sarfarazi $M$. Sequence analysis and homology modeling suggest that primary congenital glaucoma on $2 \mathrm{p} 21$ results from mutations disrupting either the hinge region or the conserved core structures of cytochrome P4501B1. Am J Hum Genet 1998;62:573-84.

15 Michels-Rautenstrauss KG, Mardin CY, Zenker M, Jordan N, GusekSchneider GC, Rautenstrauss BW. Primary congenital glaucoma: three case reports on novel mutations and combinations of mutations in the GLC3A (CYP1B1) gene. J Glaucoma 2001;10:354-7.
16 Mashima Y, Suzuki Y, Sergeev Y, Ohtake Y, Tanino T, Kimura I, Miyata H Aihara M, Tanihara H, Inatani M, Azuma N, Iwata T, Araie A. Novel cytochrome P4501B1 (CYP1B1) gene mutations in Japanese patients with primary congenital glaucoma. Invest Ophthalmol Vis Sci 2001;42:2211-6.

17 Stoilov IR, Costa VP, Vasconcellos JP, Melo MB, Betinjane AJ, Carani JC, Oltrogge EV, Sarfarazi M. Molecular genetics of primary congenital glaucoma in Brazil. Invest Ophthalmol Vis Sci 2002;43:1820-7.

18 Colomb E, Kaplan J, Garchon HJ. Novel cytochrome P450 1B1 (CYP1B1) mutations in patients with primary congenital glaucoma in France. Hum Mutat 2003;22:496.

19 Soley GC, Bosse KA, Flikier D, Flikier P, Azofeifa J, Mardin CY, Reis A, Michels-Rautenstrauss KG, Rautenstrauss BW. Primary congenital glaucoma: a novel single-nucleotide deletion and varying phenotypic expression for the 1,546-1,555dup mutation in the GLC3A (CYP1B1) gene in 2 families of different ethnic origin. J Glaucoma 2003;12:27-30.

20 Panicker SG, Reddy AB, Mandal AK, Ahmed N, Nagarajaram HA, Hasnain SE, Balasubramanian D. Identification of novel mutations causing familial primary congenital glaucoma in Indian pedigrees. Invest Ophthalmol Vis Sci 2002;43:1358-66.

21 Vincent AL, Billingsley G, Buys Y, Levin AV, Priston M, Trope G, WilliamsLyn D, Heon E. Digenic inheritance of early-onset glaucoma: CYP1B1, a potential modifier gene. Am J Hum Genet 2002;70:448-60.

22 Melki R, Belmouden A, Brezin A, Garchon HJ. Myocilin analysis by DHPLC in French POAG patients: increased prevalence of Q368X mutation. Hum Mutat 2003;22:179.

23 Beijani BA, Stockton DW, Lewis RA, Tomey KF, Dueker DK, Jabak M, Astle WF, Lupski JR. Multiple CYP1B1 mutations and incomplete penetrance in an inbred population segregating primary congenital glaucoma suggest frequent de novo events and a dominant modifier locus. Hum Mol Genet 2000;9:367-74.

24 Aklillu E, Oscarson M, Hidestrand M, Leidvik B, Otter C, IngelmanSundberg M. Functional analysis of six different polymorphic CYP1B1 enzyme variants found in an Ethiopian population. Mol Pharmacol 2002;61:586-94.

25 Bermejo E, Martinez-Frias ML. Congenital eye malformations: clinicalepidemiological analysis of 1,124,654 consecutive births in Spain. Am J Med Genet 1998;75:497-504.

26 Tielsch JM, Sommer A, Katz J, Royall RM, Quigley HA, Javitt J. Racial variations in the prevalence of primary open-angle glaucoma. The Baltimore Eye Survey. JAMA 1991;266:369-74.

27 Libby RT, Smith RS, Savinova OV, Zabaleta A, Martin JE, Gonzalez FJ, John SW. Modification of ocular defects in mouse developmental glaucoma models by tyrosinase. Science 2003;299:1578-81.

28 Sutter TR, Tang YM, Hayes CL, Wo YY, Jabs EW, Li X, Yin H, Cody CW Greenlee WF. Complete cDNA sequence of a human dioxin-inducible mRNA identifies a new gene subfamily of cytochrome P450 that maps to chromosome 2. J Biol Chem 1994:269:13092-9.

29 Bejiani BA, Xu L, Armstrong D, Lupski JR, Reneker LW. Expression patterns of cytochrome P4501B1 (Cyplb1) in FVB/N mouse eyes. Exp Eye Res 2002;75:249-57.

30 Lam DS, Leung YF, Chua JK, Baum L, Fan DS, Choy KW, Pang CP. Truncations in the TIGR gene in individuals with and without primary open-angle glaucoma. Invest Ophthalmol Vis Sci 2000;41:1386-91.

31 Watanabe J, Shimada T, Gillam EM, Ikuta T, Suemasu K, Higashi Y, Gotoh O, Kawaiiri K. Association of CYP1B1 genetic polymorphism with incidence to breast and lung cancer. Pharmacogenetics 2000;10:25-33.

32 Sasaki M, Tanaka Y, Kaneuchi M, Sakuragi N, Dahiya R. CYP1B1 gene polymorphisms have higher risk for endometrial cancer, and positive correlations with estrogen receptor alpha and estrogen receptor beta expressions. Cancer Res 2003;63:3913-8.

33 Buters JT, Sakai S, Richter T, Pineau T, Alexander DL, Savas U, Doehmer J, Ward JM, Jefcoate CR, Gonzalez FJ. Cytochrome P450 CYP1B1 determines susceptibility to 7, 12-dimethylbenz[a]anthracene-induced lymphomas. Proc Natl Acad Sci U S A 1999;96:1977-82.

34 Mammen JS, Pittman GS, Li Y, Abou-Zahr F, Bejiani BA, Bell DA, Strickland PT, Sutter TR. Single amino acid mutations, but not common polymorphisms, decrease the activity of CYPIB1 against (-)benzo[a]pyrene7R-trans-7,8-dihydrodiol. Carcinogenesis 2003;24:1247-55. 